The INL is a

U.S. Department of Energy

National Laboratory

operated by

Battelle Energy Alliance

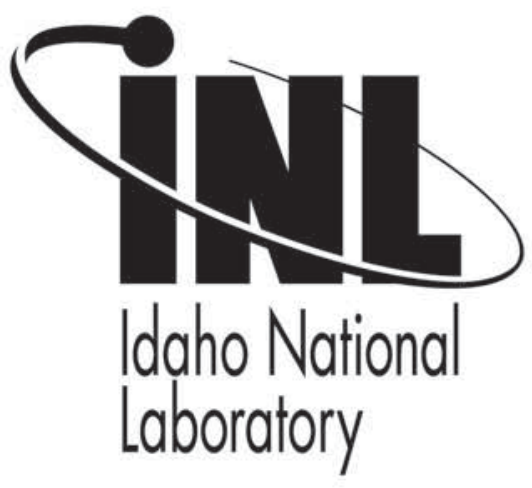

\section{Experiments Performed in Substantiation of the Conditioning of $\mathrm{BH}-350$ Spent Cesium Traps Using Lead or Lead-Bismuth Alloy Filling Technology}

\section{Materials Research Society Conference}

O. G. Romanenko

I. L. Tazhibaeva

I. L. Yakovlev

A. I. Ivanov

D. Wells

A. Herrick

J. A. Michelbacher

S. B. Shiganakov

\section{May 2009}

This is a preprint of a paper intended for publication in a journal or proceedings. Since changes may be made before publication, this preprint should not be cited or reproduced without permission of the author. This document was prepared as an account of work sponsored by an agency of the United States Government. Neither the United States Government nor any agency thereof, or any of their employees, makes any warranty, expressed or implied, or assumes any legal liability or responsibility for any third party's use, or the results of such use, of any information, apparatus, product or process disclosed in this report, or represents that its use by such third party would not infringe privately owned rights. The views expressed in this paper are not necessarily those of the United States Government or the sponsoring agency. 
Paper for MRS 2009

\title{
Experiments Performed in Substantiation of the Conditioning of BN-350 Spent Cesium Traps Using Lead or Lead-Bismuth Alloy Filling Technology.
}

\author{
O.G. Romanenko ${ }^{1}$, I.L. Tazhibaeva ${ }^{1}$, I.L. Yakovlev ${ }^{2}$, A.I. Ivanov $^{2}$, D. Wells ${ }^{3}$, A. Herrick ${ }^{3}$, J.A. \\ Michelbacher ${ }^{4}$, S.B. Shiganakov ${ }^{5}$. \\ ${ }^{1}$ Nuclear Technology Safety Center (RK) \\ ${ }^{2}$ MAEC Kazatomprom (RK) \\ ${ }^{3}$ Nuvia Limited (UK) \\ ${ }^{4}$ Idaho National Laboratory (USA) \\ ${ }^{5}$ Kazakh Atomic Energy Committee (RK)
}

\begin{abstract}
The technology of cleaning cesium radionuclides from sodium coolant at the $\mathrm{BN}-350$ fast reactor was realized in the form of cesium traps of two types: stationary devices connected to the circuit that was to be cleaned and in-core devices installed into the core of reactor when it was not under operation. Carbon-graphite materials were used as sorbents to collect and concentrate radioactive cesium, accumulated in the $\mathrm{BN}-350$ reactor circuits over the decades of their operation, in relatively small volume traps which provided effective radiation-safe conditions for personnel working in proximity to the coolant and equipment of the primary circuit during BN350 decommissioning. Spent cesium traps, as products unfit for further use, represent solid radioactive wastes. The presence of chemically active sodium, potassium and cesium that are able to react violently with water results in series of problems related to their disposal in the Republic of Kazakhstan. Considering the technology of filling spent cesium traps with lead/lead-bismuth alloy as a priority one for their conditioning, evaluations for safety substantiation were implemented. A set of experiments was implemented aimed at verification of calculations performed in substantiation of the proposed technology: filling a full scale cesium trap mock-up with sodium followed by its draining to determine the optimal regimes of draining; filling bench scale cesium trap mock-ups with sodium and cesium followed by sodium draining and filling with lead or lead-bismuth alloy at different temperatures and filling rates to chose the optimal regimes for filling spent cesium traps; implementation of leachability tests to determine the rate of cesium release from the filling materials into water. This paper provides a description of the experimental program carried out and the main results obtained.
\end{abstract}

\section{INTRODUCTION}

All reactor systems have to allow for the occurrence of leakage of radio-active fission products from normally sealed fuel pins and the resulting contamination of the coolant. Any tendency for the coolant activity to increase over time to a level which causes operational or safety problems must therefore be counteracted by the provision of routine or periodic coolant clean-up processes. For water reactors, such clean-up is routinely arranged using ion exchange systems, supplemented as necessary by chemical decontamination campaigns. However, although the liquid metal cooled fast reactor is no different from other reactor types in requiring coolant clean-up, aqueous processes and large scale coolant replacement is out of the question. Fast reactor designers therefore developed the so-called "cesium trap" to remove the dominant radionuclide of concern $-\mathrm{Cs}^{137}$ in sodium. 
During the different periods of BN-350 fast breeder reactor operation two types of cesium trap were used: in-core devices designed by the Research Institute of Atomic Reactors (NIIAR), Dimitrovgrad, Russia (the "MAVR" series, using low ash granulated graphite (LAG)) and stationary devices using reticulated vitreous carbon (RVC), designed by the Institute of Atomic Energy of the Republic of Kazakhstan's National Nuclear Center (IAE NNC RK), ANL (now Idaho National Laboratory - INL) and MAEC Kazatomprom, the operator of BN-350 [1]. At present, 4 spent cesium traps of the MAVR series and 7 spent trap accumulators (TA) are stored at BN-350. The filled cesium traps have high specific activity and are contaminated with varying amounts of sodium - therefore they are not suitable for long term storage or disposal due to the mobility of radioactivity and chemical reactivity. Characterization of the traps and optioneering for handling of BN-350 spent cesium traps was accomplished earlier [2]. Conditioning of all cesium traps by filling with lead or lead-bismuth (Pb-Bi) alloy, based on Russian technology [3, 4] was proposed as the preferred technology, recognizing that additional experimental verification was required. The aim of the work reported below was thus to confirm the process for conditioning or immobilizing the BN-350 cesium traps to improve their physical security and safety for long term storage, as part of the overall process of decommissioning of the plant.

\section{EXPERIMENTS PERFORMED TO SUBSTANTIATE Pb/Pb-Bi FILL METHOD}

Since the technology for lead $(\mathrm{Pb})$ filling of low ash graphite pebble adsorbers has already been tested by NIIAR, Russia [3, 4], there was high confidence that this approach could be applied for conditioning BN-350 spent cesium traps of the MAVR series. Nevertheless, there were still questions regarding the advantages and disadvantages of filling cesium traps with eutectic alloy $\mathrm{Pb}-\mathrm{Bi}\left(55.5 \% \mathrm{Bi}-44.5 \% \mathrm{~Pb}\right.$, melting point $\left.125^{\circ} \mathrm{C}\right)$ at lower temperatures compared to that for lead which has a melting point of $327^{\circ} \mathrm{C}$. Experiments on filling of RVC adsorbers had not previously been performed, so it was hard to predict reliably if $\mathrm{Pb} / \mathrm{Pb}-\mathrm{Bi}$ would uniformly fill this type of sorbent. The conditioning technology for filling Trap Accumulators with $\mathrm{Pb} / \mathrm{Pb}-$ Bi bore many uncertainties about the optimal parameters such as rate of fill, temperature of fill, etc. Additionally, TAs are filled with sodium which cannot easily be drained, while sodium is fully drained from the MAVRs. Therefore sodium draining experiments needed to be implemented on the TAs in order to determine how much sodium could be removed and how much would remain to determine the phase composition of $\mathrm{Pb}-\mathrm{Na}$ alloy in the conditioned traps.

The objective of the experimental program was to determine the following parameters of $\mathrm{Pb} / \mathrm{Pb}-\mathrm{Bi}$ fill related to conditioning of both TAs and MAVRs: optimal content of the filler and temperature of fill; optimal heating temperature of the trap under depressurization; extent of release of aerosols from the trap under depressurization and during fill; optimal rate of fill. The cesium redistribution between sorbents and filler matrix after filling traps with $\mathrm{Pb} / \mathrm{Pb}$ - $\mathrm{Bi}$ also needed to be determined. Finally, the leachability of $\mathrm{Cs}^{137}$ from the conditioned traps needed to be determined experimentally in order to substantiate their long term storage safety. Both small size and full scale mock-ups were used in the experiments to obtain the data needed.

\section{Sodium draining from Trap Accumulators}

A full scale mock-up of a TA was fabricated and loaded with 3,07 kg of RVC corresponding to the maximum amount of RVC in any of the traps. The mock-up was filled with sodium and weighed. Then, sodium was drained from the trap and the non-drainable amount of sodium was 
determined by a repeat weighing. It was shown that more than $80 \%$ of the sodium could be drained from a Trap Accumulator.

\section{Filling experiments with lead/lead -bismuth alloy}

Filling experiments were carried out with bench scale mock-ups of the two types of cesium trap and included the following actions: filling bench scale mock-ups of TAs and MAVRs with sodium and their saturation with cesium; filling mock-ups with lead or lead-bismuth at different rates and temperatures; sectioning of mock-ups; investigation of element distribution along the mock-ups; measurement of the leachability of $\mathrm{Cs}^{137}$ from the filled mock-ups.

\section{Saturation of sorbent with cesium}

Stainless steel tubes filled with RVC or low ash graphite sorbent were used as bench scale mock-ups in these experiments. A mixture of non-radioactive sodium with a stable isotope of cesium and a small amount of BN-350 primary sodium as a source of $\mathrm{Cs}^{137}$ was used for saturating the bench scale mock-ups with cesium. The total concentration of cesium in sodium was adjusted to provide a concentration of cesium in the trap mock-ups corresponding to the maximum values of cesium in the BN-350 spent traps. The unstable radionuclide of cesium, $\mathrm{Cs}^{137}$, was used as a tracer element to measure cesium release from the mock-ups during filling, as well as for measuring the rate of leachability from the filled mock-ups.

Saturation of sorbent with cesium was carried out by passing sodium from a melting tank through seven bench scale mock-ups arranged in parallel, see Figure1. Seven mock-ups with RVC were saturated with cesium in the first run and seven mock-ups with LAG in the second. Each time before passing sodium through the set of mock-ups, $100 \mathrm{~kg}$ of non-radioactive sodium

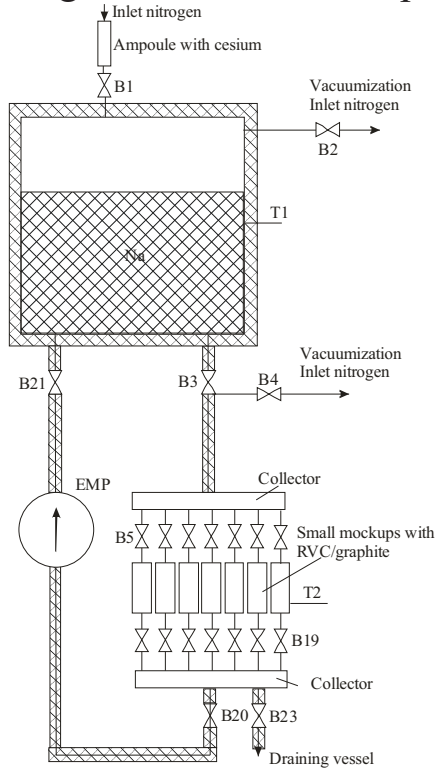

Fig.1. Experimental installation for saturation of the mock-ups with cesium.

in the system was mixed with $1.5 \mathrm{~kg}$ of primary sodium and $25 \mathrm{~g}$ of stable cesium was added into the system by means of a specially designed feeder. The sequence of saturation was as follows: fill sodium melting tank with $100 \mathrm{~kg}$ of secondary sodium; add $25 \mathrm{~g}$ of stable cesium into sodium melting tank; add $1,5 \mathrm{~kg}$ of primary sodium into sodium melting tank; heat up system to 180$200^{\circ} \mathrm{C}$; sodium circulation through mock-ups for 30 minutes (until stabilization of radiation dose 
rate from the mock-ups); de-energize electro-magnetic pump; drain sodium from the mock-ups, displace sodium from mock-ups with nitrogen; de-energize heaters.

\section{Cesium release during lead/lead-bismuth fill of small size mock-ups}

Lead/lead-bismuth fill experiments were carried out according to the following sequence: assembly of the experimental installation represented in figure 2 and filling of the melting tank with lead or lead-bismuth alloy; depressurizing of the system; heat system up; fill of one bench scale mock-up with lead or lead-bismuth under gravity until the moment when the level of lead or lead-bismuth alloy reaches the level meter of the mock-up; de-energizing of the heaters; substitution of one filled mock-up for the next.

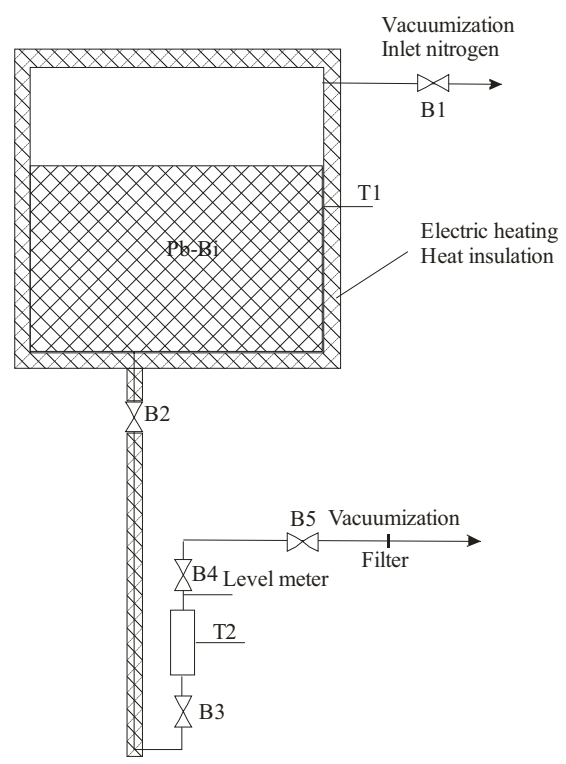

Fig.2. Experimental installation for lead/lead-bismuth alloy fill experiments.

Filling rate was regulated by the $\mathrm{B} 2$ valve below the melting tank. Bench scale mock-ups were filled with lead at $350^{\circ} \mathrm{C}$ and with lead-bismuth alloy at $150^{\circ} \mathrm{C}$ and $250^{\circ} \mathrm{C}$. Two filling rates were used: $2 \mathrm{~mm} / \mathrm{s}$ and $20 \mathrm{~mm} / \mathrm{s}$. When filling a mock-up with lead or lead-bismuth alloy the outlet from the mock-up was connected to the special ventilation system through a filter, which was changed after each fill. The radionuclide activity released and captured on the filter during each fill procedure was measured by means of a gamma spectrometer. Data related to filling of small size mock-ups with lead or lead-bismuth are presented in Table I.

Table I. Data related to filling of small size mock-ups with lead or lead-bismuth

\begin{tabular}{|c|c|c|c|c|c|}
\hline \multirow{2}{*}{$\begin{array}{l}\text { \# Mock-up } \\
\text { and type of } \\
\text { sorbent }\end{array}$} & \multirow{2}{*}{$\begin{array}{l}\text { Activity of mock-up } \\
\text { after saturation with Cs, } \\
\qquad \mathbf{B q}\end{array}$} & \multicolumn{3}{|c|}{$\begin{array}{l}\text { Regime of filling mock-ups with lead or lead } \\
\text { bismuth alloy }\end{array}$} & \multirow{2}{*}{$\begin{array}{c}\text { Activity } \\
\text { on filter } \\
\left(\mathbf{C s}{ }^{137}\right), \\
\text { Bq }\end{array}$} \\
\hline & & Filler & $\begin{array}{c}\text { Filling } \\
\text { temperature, } \\
{ }^{0} \mathrm{C}\end{array}$ & $\begin{array}{l}\text { Filling time, } \\
\text { s }\end{array}$ & \\
\hline $1 \mathrm{RVC}$ & $3,97 \times 10^{5}$ & Pb-Bi alloy & 250 & 32 & 4,1 \\
\hline $2 \mathrm{RVC}$ & $4,3 \times 10^{5}$ & $\mathrm{~Pb}$ & 350 & 240 & 41,7 \\
\hline $5 \mathrm{RVC}$ & $3,84 \times 10^{5}$ & $\mathrm{~Pb}$ & 350 & 32 & 62,9 \\
\hline $6 \mathrm{RVC}$ & $3,1 \times 10^{5}$ & $\mathrm{~Pb}-\mathrm{Bi}$ alloy & 250 & 250 & 5,1 \\
\hline $9 \mathrm{RVC}$ & $1,3 \times 10^{5}$ & Pb-Bi alloy & 150 & 32 & 5,0 \\
\hline
\end{tabular}




\begin{tabular}{|c|c|c|c|c|c|}
\hline $3 \mathrm{LAG}$ & $3,84 \times 10^{5}$ & $\mathrm{~Pb}$ & 350 & 45 & 5,8 \\
\hline $4 \mathrm{LAG}$ & $3 \times 10^{5}$ & $\mathrm{~Pb}-\mathrm{Bi}$ alloy & 250 & 34 & 4,4 \\
\hline $7 \mathrm{LAG}$ & $3,8 \times 10^{5}$ & $\mathrm{~Pb}$ & 350 & 245 & 5,75 \\
\hline $8 \mathrm{LAG}$ & $5,2 \times 10^{5}$ & $\mathrm{~Pb}-\mathrm{Bi}$ alloy & 250 & 245 & 3,8 \\
\hline
\end{tabular}

The data represented in Table I show that filling temperature strongly influences the release of cesium radionuclides from RVC sorbent. A temperature increase from $250^{\circ} \mathrm{C}$ to $350^{\circ} \mathrm{C}$ results in a ten-fold increase of activity released from the RVC. This effect is not so pronounced for the LAG sorbent. The maximum measured cesium release fraction from RVC is $1.6 \times 10^{-4}$, which would give about $2 \mathrm{Ci}$ release of cesium radionuclides from the spent $\mathrm{TA}$ with maximum activity (3800Ci [1]). Such an amount of cesium released could be easily trapped by a filter installed in the ventilation system of the installation designed for conditioning BN-350 spent cesium traps.

\section{Lead fill - filling temperature $350^{\circ} \mathrm{C}$}

After filling, the bench scale mock-ups were split into longitudinal half sections by means of a milling machine. Diametral cuts were not implemented. The area and position of any cavities in the filled mock-ups were estimated after sectioning. Although filling with lead had been carried out at different rates, there was no noticeable effect regarding the quality of fill. Possibly any effect was masked by the fact that the sorbent was immersed in the lead for a substantial time during the cooling down procedure, compared with only 30-250 seconds of filling time. Good filling and wettability of both RVC and LAG with lead were observed, Figs. 3, 4.

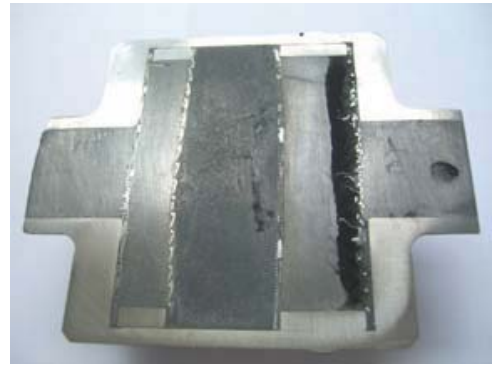

Fig 3. Bench scale mock-up of TA filled with lead

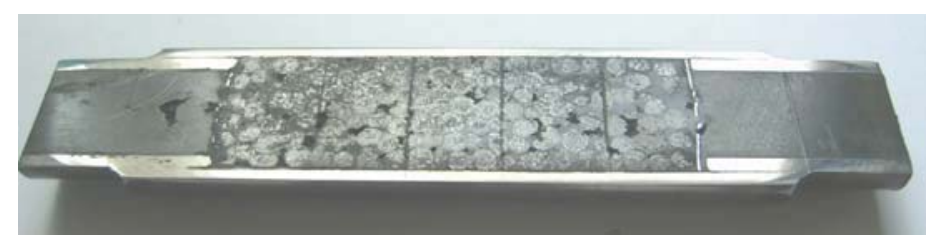

Fig. 4. Bench scale mock-up of MAVR filled with lead

The surfaces of sectioned mock-ups filled with lead were investigated using a JSM-6480LA Scanning Electron Microscope (SEM). Elemental composition was determined along the mockups at intervals of $15-20 \mathrm{~mm}$. There was some difficulty in obtaining precise data relating to the bulk element composition due to the fact that there was continuous coverage of the sectioned surface with sodium, followed by its oxidation. Nevertheless, SEM analysis showed that cesium release from RVC/LAG into the lead matrix did not exceed $15 \%$. Sodium presence at concentrations between 3-20\% was detected at all points along the surfaces of half sections where elemental composition analysis was undertaken. When filler material was fractured it demonstrated a brittle behavior with fracturing along the grain boundaries. Any fracture surface of the filler was rapidly covered with sodium followed by its oxidation, with the rate significantly exceeding that observed for the surfaces of the mock-up half sections. These data drew the conclusion that sodium is generally distributed homogeneously in the filler with some preference to segregate at the grain boundaries, which causes rather high brittleness of the filler. 


\section{Lead-bismuth fill - filling temperature $250^{\circ} \mathrm{C}$}

Filling of mock-ups with lead-bismuth was carried out at different filling rates but, again, there was no noticeable effect regarding the quality of fill. Good filling and wettability of both RVC and LAG was obtained. SEM analysis did not reveal a pronounced decrease in the amount of cesium released from $\mathrm{RVC} / \mathrm{LAG}$ into the $\mathrm{Pb}$-Bi matrix compared to that for mock-ups filled with lead at $350^{\circ} \mathrm{C}$.

\section{Lead-bismuth fill - filling temperature $150^{\circ} \mathrm{C}$}

A filling temperature decrease of $100^{\circ} \mathrm{C}$ to $150^{\circ} \mathrm{C}$ resulted in problems with the filling procedure. It only proved possible to fill one mock-up loaded with $\mathrm{RVC}$ at this temperature, while the level of lead-bismuth alloy did not reach the level indicator. After sectioning the mockup it was found that a plug, containing an increased concentration of bismuth and sodium, had formed in the upper part of the valve. Other mock-ups could not be filled with the lead-bismuth eutectic alloy at $150^{\circ} \mathrm{C}$ due to creation of plugs in the inlet piping of the mock-ups. It is considered likely that a compound with increased melting point was created but it was not distributed homogeneously in the upper part of the alloy as happened at $250^{\circ} \mathrm{C}$ and it floated to the surface as a foam which plugged the valves at the lower temperature. Elemental composition of this plug was determined by means of SEM and high concentrations of bismuth and sodium were found: $\mathrm{Bi}-53,4 \%$ (mass); $\mathrm{Pb}-9,2 \%$ (mass); $\mathrm{Na}-15,4 \%$ (mass). Nevertheless, the wettability of RVC with the $\mathrm{Pb}-\mathrm{Bi}$ alloy also appeared to be good for this case.

\section{Discussion of filling results obtained}

All the small size mock-ups filled with lead or lead-bismuth alloy have small cavities. Probably, there are two reasons explaining their appearance - alloy shrinkage during solidification and gas release from the sorbent while implementing the filling procedure. When filling the mock-ups with lead - bismuth alloy there was a redistribution of lead and bismuth concentrations during mixing with sodium in the mock-up. The ratio of lead-bismuth was 1:1 at the inlet of the mock-up, while once alloy had passed through the mock-up this ratio changed to $3 \div 5: 1$, a decrease of several times in the bismuth concentration. Thus, one may conclude that inter-metallic compounds of bismuth and sodium were created and these tried to float to the upper part of the mock-up.

No problems were found with operation of the valves that were in contact with sodium and then with lead. However as noted above, after operating with lead-bismuth alloy at $150^{\circ} \mathrm{C}$ a plug containing an increased concentration of bismuth and sodium was found in the upper part of the valve.

$\mathrm{SEM}$ analysis showed that cesium release from $\mathrm{RVC} / \mathrm{LAG}$ into the $\mathrm{Pb} / \mathrm{Pb}-\mathrm{Bi}$ matrix did not exceed $15 \%$. However, this activity is retained within the solidified filler metal matrix.

\section{$\underline{\text { Leachability tests using filled bench scale cesium trap mock-ups }}$}

A key objective for performing leachability tests was to prove that radionuclides could be captured by the filler matrix effectively after the fill procedure. In accordance with Kazakhstani requirements the rate of $\mathrm{Cs}^{137}$ leachability should not exceed $1 \times 10^{-3} 1 /\left(\mathrm{cm}^{2} \times\right.$ day $)$ for conditioned solid radioactive wastes.

One bench scale TA mock-up (loaded with RVC) and one bench scale MAVR mock-up (loaded with LAG) were filled with lead under the derived optimal regime. Leachability tests 
were performed with the mock-ups sectioned into two parts as well as with the non-sectioned mock-ups after cutting off their inlet and outlet pipes. Normal water was used as the solution for the leachability tests. The solution was substituted for a new one following 1, 2, 3, 7, 14, 21, 28 days of exposure and its activity was measured. The rate of $\mathrm{Cs}^{137}$ leachability, $1 /\left(\mathrm{cm}^{2} \times\right.$ day $)$ was calculated using the following equation 1:

$$
R_{n}=\frac{a_{n}}{A_{0} \cdot F \cdot t_{n}}
$$

Where: $a_{n}$ is $\mathrm{Cs}^{137}$ activity in the solution, $\mathrm{Bq} ; A_{0}$ is initial activity of $\mathrm{Cs}^{137}$ in sorbent, $\mathrm{Bq} ; F$ open geometrical surface of the sample, $\mathrm{cm}^{2} ; t_{n}$ - time of leaching, days.

Results of leachability tests are represented in Table II.

Table II. Results of leachability tests

\begin{tabular}{|c|c|c|c|c|c|}
\hline \multirow{2}{*}{ Specimen } & \multicolumn{5}{|c|}{ Rate of leachability, $1 /\left(\mathrm{cm}^{2} \times\right.$ day $), \times 10^{-6}$} \\
\hline & 1 day & 7 days & 14 days & 21 days & 28 days \\
\hline Whole mock-up with RVC & 6,46 & 1,72 & 0,31 & 0,13 & 0,09 \\
\hline Whole mock-up with LAG & 41,39 & 5,11 & 1,89 & 1,22 & 0,78 \\
\hline Half of the mock-up with RVC & 3322,96 & 604,32 & 297,66 & 153,10 & 127,53 \\
\hline Half of the mock-up with LAG & 2049,67 & 133,34 & 27,56 & 9,56 & 5,57 \\
\hline
\end{tabular}

The rate of $\mathrm{Cs}^{137}$ leachability from the whole mock-up loaded with low ash graphite is higher than that for a whole mock-up loaded with RVC. This suggests better binding between cesium and $\mathrm{RVC}$ resulted in lower release of cesium into the lead matrix compared to that for low ash graphite. The rate of $\mathrm{Cs}^{137}$ leachability from the half of the mock-up loaded with RVC is higher than that for the half mock-up loaded with LAG. This can be interpreted to suggest that the surface area of low ash graphite pebbles in contact with the leaching water is significantly smaller than the surface area of RVC material exposed to the water. The rates of $\mathrm{Cs}^{137}$ leachability from the whole mock-ups meet Kazakhstani requirements for conditioned solid radioactive wastes, while the halves of the mock-ups meet these requirements after 7 days of leaching.

\section{CONCLUSIONS}

The experiments reported above substantiate the lead/lead-bismuth fill technique for conditioning BN-350 spent cesium traps. It was shown that more than $80 \%$ of the sodium could be drained from the Trap Accumulators as the initial phase of their conditioning. The experiments on small scale mock-ups demonstrated that lead/lead-bismuth filling and wettability are good for both RVC and LAG. After cooling down the filled mock-ups, small cavities were found in the samples, due possibly to shrinkage of the filler during solidification as well as by gas release from the sorbents during the fill. These small cavities are not considered detrimental to the effectiveness of the immobilization of the activity in the traps. Lead-bismuth alloy fill of the mock-ups at $150^{\circ} \mathrm{C}$ was implemented only in one case. Attempts to repeat this procedure for other mock-ups failed due to the creation of solid plugs in the system. 
When filling mock-ups with lead-bismuth alloy, the alloy composition changed from inlet to outlet along the mock-ups due to the creation of sodium-bismuth compounds floating in an upward direction, which, in turn resulted in a decrease of bismuth concentration in the alloy down to a ratio $3 \div 5: 1$ at the mock-up outlet.

The rate of cesium release from the sorbents into the gas phase is acceptably low during filling. The maximum cesium release fraction from RVC was $1.6 \times 10^{-4}$, while this value for LAG was $10^{-5}$ when filling mock-ups with lead at $350^{\circ} \mathrm{C}$. Cesium release from RVC/LAG into the lead/lead-bismuth matrix did not exceed $15 \%$ in the filled mock-ups but the activity is retained within the solidified filler metal matrix.

The rate of $\mathrm{Cs}^{137}$ leachability meets the Kazakhstani requirements for the whole mock-ups immediately after a fill procedure, while the rate of $\mathrm{Cs}^{137}$ leachability for the halves of the mockups achieves the allowable value after seven days of leaching.

As a result of these experiments, the lead fill technique can be recommended for conditioning BN-350 spent cesium traps.

\section{ACKNOWLEDGEMENTS}

The work reported above was undertaken under an extension to ISTC Project K-512 funded by the UK Government Department of Energy and Climate Change (DECC). The authors gratefully acknowledge DECC's approval to publish this paper.

\section{REFERENCES}

1. O.G. Romanenko, K.J. Allen, D.M. Wachs, H.P. Planchon, P.B. Wells, J.A. Michelbacher, P. Nazarenko, I. Dumchev, V. Maev, B. Zemtzev, L. Tikhomirov, V. Yakovlev, A.Synkov, Nuclear Technology 150, 79 (2005).

2. O.G. Romanenko, I.L. Tazhibaeva, D. Wells, A. Herrick, J.A. Michelbacher, C. Knight, V.I. Polyakov, U. Privalov, M. Sobolev, U Shtynda, A. Gaynullina, I.L. Yakovlev, U.P. Shirobokov, A.I. Ivanov, G.P. Pugachev, "Strategy for Handling Spent BN-350 Cesium Traps in the Republic of Kazakhstan", Safety Related Issues of Spent Nuclear Fuel Storage, ed. J.D.B. Lambert and K.K. Kadyrzhanov (Springer 2007) pp.107-142.

3. V.D. Kizin, V.I. Polyakov, A.V. Sobolev, "Preparation of radionuclide traps of sodium cooled reactors for disposal", Report for Russian-French seminar on treatment of radioactive sodium wastes, Dimitrovgrad, Russia, 15-16 October, 1998.

4. V.D. Kizin, Y.E. Shtynda, Cesium Trap Conditioning for Disposal, IAEA meeting, "Radioactive Sodium Waste Treatment and Conditioning", Lyon, France (2002). 